\title{
PRÁTICAS DE FORMAÇÃO COLABORATIVA NO PROCESSO DE LEITURA E ESCRITA DE UM ALUNO COM TRANSTORNO FUNCIONAL ESPECÍFICO ${ }^{1}$
}

\author{
Cristiane Malinoski Pianaro Angelo* \\ Maria Andreia Batista Blum ${ }^{* *}$ \\ Eliziane Manosso Streiechen ${ }^{* * *}$
}

RESUMO: Este artigo tem por objetivo discutir como a mediação pedagógica colaborativa contribui para a docência e para a aprendizagem do aluno que apresenta transtornos funcionais específicos TFE, relacionados às dificuldades em ler e escrever. Com fundamentos teóricos nos estudos do Círculo de Bakhtin e na teoria histórico-cultural, a partir de Vygotsky, e com base metodológica nos pressupostos da pesquisa colaborativa, buscou-se orientar uma professora do $4^{\circ}$ ano do ensino fundamental no trabalho com a leitura e a escrita junto ao aluno que apresenta TFE. Os resultados demonstram a mudança de atitude da professora em sala de aula, a partir das atividades de formação desenvolvidas, visto que esta passa a valorizar os saberes do aluno e a trabalhar práticas de leitura e de escrita pautadas nos princípios dialógicos; demonstram, também, avanços significativos do aluno com TFE em seu desenvolvimento, não só perante a leitura e a escrita, como também suas relações sociais.

PALAVRAS-CHAVE: Transtornos funcionais específicos; Leitura e escrita; Formação continuada; Pesquisa colaborativa.

\footnotetext{
${ }^{1}$ Pesquisa desenvolvida com apoio da UNICENTRO e da Fundação Araucária, por meio do Programa Institucional de Pesquisa Básica e Aplicada da Fundação Araucária, Projeto "Leitura e escrita: dificuldades de ensino e aprendizagem no Ensino Básico".

* Doutora em Letras pela Universidade Estadual de Maringá (Uem). Professor da Universidade Estadual do Centro-Oeste (Unicentro).

** Mestre em Letras pela Universidade Estadual do Centro-Oeste (Unicentro).

${ }^{* * *}$ Doutora em Educação. Docente do Departamento de Letras da Universidade Estadual do Centro-Oeste (Unicentro).
} 


\section{Considerações iniciais}

No Brasil, desde a década de 1990, intensificaram-se os investimentos, as leis e os estudos em prol da inclusão escolar de alunos com deficiências (UNESCO, 1994). Em decorrência disso, na atualidade, são percebidas muitas iniciativas voltadas à educação inclusiva, que levam em conta apenas esses indivíduos. Uma dessas iniciativas é o Atendimento Escolar Especializado - AEE - que é um serviço da Educação Especial para atender alunos que apresentam deficiência física, intelectual, visual, auditiva, múltiplas, transtorno do espectro autista e também alunos com altas habilidades/superdotação (BRASIL, 2009). Contudo, há uma expressiva carência em pesquisas e políticas públicas que discutam e atendam alunos que apresentam outras condições peculiares de aprendizagem ${ }^{2}$. Esses alunos, embora não carreguem o estereótipo de deficiência aparente, deparam-se com conflitos em seu processo escolar, ficando à margem e fadados ao 'fracasso'. Alunos que apresentam Transtorno Específico da Aprendizagem - ou Transtorno Funcional Específico TFE, em nossa compreensão, fazem parte desse grupo, uma vez que, em muitos casos, eles tornam-se invisíveis aos olhos de muitos educadores e excluídos de um efetivo processo de ensino e aprendizagem.

A legislação nacional não prevê o AEE para as pessoas com TFE, visto que não são consideradas pessoas com necessidades educacionais especiais - NEE. Entretanto, por necessitarem de um trabalho pedagógico diferenciado, devido às dificuldades na aprendizagem e no uso de habilidades acadêmicas, como a leitura, a escrita e a matemática (APA, 2014), a legislação do Estado do Paraná, como exceção, estende o atendimento aos alunos com TFE, definindo-os como "aqueles que apresentam transtorno de aprendizagem, como disgrafia, disortografia, dislexia, discalculia ou transtorno de déficit de atenção/hiperatividade, entre outros" (PARANÁ, 2016, p. 8). Desse modo, no Paraná, o aluno com TFE

\footnotetext{
${ }^{2}$ Streiechen (2018), fundamentada em Pedrinelli e Verenguer (2008), utiliza a expressão 'alunos com condições peculiares de aprendizagem', por entender que a terminologia agrega todos os alunos, com ou sem deficiência, que encontram algum tipo de desafio ou barreira em seu processo de escolarização.
} 
frequenta a classe regular e, em turno inverso à escolarização, pode cursar a Sala de Recursos Multifuncionais - SRM, que é um "espaço organizado com material didático, profissionais da educação especializados e de apoio aos alunos e professores, recursos pedagógicos, tecnológicos, de acessibilidade, objetivando a oferta do Atendimento Educacional Especializado (PARANÁ, 2016, p. 11).

Para atender o aluno com TFE, em classe comum e, no caso do Paraná, em SRM, é fundamental que os professores recebam formação adequada, tanto inicial como continuada, para que no exercício da profissão saibam reconhecer as características desse transtorno e tenham condições de avaliar as metodologias mais adequadas para favorecer a participação plena e efetiva desse aluno no processo educacional, em igualdade de condições com os demais estudantes.

A fim de problematizar algumas questões, como a falta de formação na docência e de políticas públicas para o atendimento de alunos com TFE, desenvolvemos uma pesquisa colaborativa (DESGAGNÉ, 2007; JESUS et. al, 2014) junto a uma professora que, na ocasião da pesquisa, atuava em um $4^{\circ}$ ano do Ensino Fundamental, classe na qual se encontrava matriculado um aluno com TFE - e, no turno inverso, atuava em uma SRM, no atendimento a esse aluno e a outros com NEE. Nesse contexto, pretendemos discutir os resultados da experiência colaborativa no processo de ensino e aprendizagem da leitura e da escrita desse educando.

A experiência foi fundamentada nos pressupostos da teoria dialógica do Círculo de Bakhtin $^{3}$ (BAKHTIN/VOLOCHINOV, 2006; BAKHTIN, 2003) e da teoria HistóricoCultural (VYGOTSKY, 1991; 1998), as quais conferem à linguagem uma natureza social, portanto fundada nas inter-relações entre sujeitos. Para Vygotsky (1991), as relações interpessoais desempenham papel fundamental no desenvolvimento humano, pois, por meio

${ }^{3} \mathrm{O}$ Círculo de Bakhtin foi um grupo formado por intelectuais de diversas áreas do conhecimento que se reuniam regularmente entre 1919 a 1929, na Rússia, com interesses e problemáticas diversificadas. O mais conhecido integrante do Círculo foi o filósofo Mikhail Mikhailovitch Bakhtin. 
da mediação do outro, aquilo que é zona de desenvolvimento proximal - ZDP hoje, será o nível de desenvolvimento real - NDR amanhã, isto é, aquilo que o sujeito pode fazer com assistência hoje, ele terá condições de fazer sozinho amanhã. Da mesma forma, as relações interpessoais mediadas pela linguagem no contexto da formação continuada são imprescindíveis para que o professor tome consciência acerca de suas ações na sala de aula e aprenda a avaliar e redimensionar as suas próprias práticas, desenvolvendo-se como sujeito.

\section{Aspectos teóricos da pesquisa}

No processo de formação inicial ou continuada, o professor não absorve integralmente aquilo que lhe foi apresentado como uma operação externa, mas constrói novas aprendizagens, de modo a ressignificar processos com os quais já está habituado. Como explica Vygotsky (1991, p. 41), “todas as funções no desenvolvimento [...] aparecem duas vezes: primeiro, no nível social, e, depois, no nível individual; primeiro, entre pessoas (interpsicológica), e, depois, no interior [...] (intrapsicológica)". Assim, o educador pode transformar a palavra do outro em palavra própria, seja esse outro o professor formador, o pesquisador, os colegas professores ou a teoria que fundamenta e amplia os conceitos em questão. Essas considerações aproximam-se dos pressupostos do dialogismo (BAKHTIN/VOLOCHINOV, 2006; BAKHTIN, 2003), os quais evidenciam que todo enunciado é um diálogo, que se constrói a partir de outros que o antecederam e gera enunciados novos.

A partir dos estudos desenvolvidos pelo Círculo de Bakhtin, muitos conceitos relacionados à linguagem tomaram perspectivas diversas das defendidas até então por teorias que tratavam a língua separando-a dos contextos onde ela se manifestava, ora a esmiuçando pedagogicamente em fonética, gramática e léxico, novamente descontextualizando-a das situações comunicativas. Na perspectiva bakhtiniana, o texto/enunciado/discurso só pode ser assim caracterizado quando produzir sentido, significação e gerar no outro uma resposta, uma construção nova, fruto de uma compreensão responsiva ativa. 
Segundo Bakhtin/Volochinov (2006), a maioria dos estudos linguísticos volta-se particularmente para o som, exaurindo-se em conceitos fonéticos que procuram explicações para a diversidade peculiar à língua falada. Entretanto, de acordo com os teóricos, somente o som isolado, como fenômeno puramente acústico, acaba desvinculando a linguagem de sua especificidade: a comunicação. Somente o som inserido em uma esfera social, na qual os signos sejam carregados de significado, onde haja um locutor e um ouvinte pertencentes a uma mesma comunidade linguística, inseridos em um contexto social, será capaz de constituir significação linguística, experiências comunicativas complexas que dependem de inúmeros elementos, tanto verbais quanto visuais, para constituir o que se denomina "linguagem" (BAKHTIN/VOLOCHINOV, 2006).

A significação, intimamente atrelada ao contexto comunicativo e ao campo de conhecimento linguístico do aluno, é fator fundamental para que a aprendizagem possa ocorrer. Tendo em vista as diferentes experiências - culturais e de apropriação de conhecimento - dos alunos que compõem as salas de aula, torna-se necessário um ensino que priorize a individualidade e a inserção funcional, contextualizada, das práticas da leitura e da escrita, para que, assim, se constituam sujeitos responsivos, participantes da vida escolar e social.

Para Vygotsky (1991), o aprendizado e o desenvolvimento são enraizados na cultura e acontecem historicamente pela inter-relação entre indivíduos, pela estimulação do meio e internalização das ações.

O conceito de zona de desenvolvimento proximal - ZDP (VYGOTSKI, 1991), nessa pesquisa, fundamenta todo o trabalho colaborativo, visto que o papel do outro, da intervenção colaborativa, tende a proporcionar aprendizagem que aumenta o desenvolvimento gradativamente. Quanto maior for o trabalho que potencialize o alcance das metas estabelecidas dentro da ZDP, tanto maior será a abrangência de novos objetivos a serem alcançados e, assim, sucessivamente.

Desse modo, no âmbito da pesquisa colaborativa, a apropriação se dá a partir da utilização de instrumentos, sejam materiais ou simbólicos (signos), que podem subsidiar o desenvolvimento do professor em formação, com intuito de levá-lo a refletir e transformar sua prática em sala de aula. 


\section{Método}

Esta é uma pesquisa do tipo qualitativa, com abordagem colaborativa, visto que o interesse de investigação "[...] se baseia na compreensão que os docentes constroem, em interação com o pesquisador, acerca de um aspecto da sua prática profissional, em contexto real” (DESGAGNÉ, 2007, p. 10). Nesse sentido, toma-se o contexto real da sala de aula para demonstrar como o trabalho colaborativo junto ao professor pode contribuir para o atendimento ao aluno com TFE.

A pesquisa ${ }^{4}$ foi realizada em uma escola municipal de ensino fundamental, localizada no interior do Estado do Paraná. Participaram do estudo, além de uma das pesquisadoras - que desenvolveu as experiências colaborativas - a professora do $4^{\circ}$ ano, aqui denominada PSR, que no decorrer da pesquisa passou a atuar também na SRM. Outro participante da pesquisa é um aluno, denominado Davi, nove anos de idade, que frequentava a sala de aula comum, no período matutino, e a SRM em turno contrário, duas vezes por semana, com a mesma professora. Ressaltamos que esse aluno estava repetindo pela segunda vez o $4^{\circ}$ ano. Davi apresenta TFE, conforme laudos especializados registrados pela escola.

A referida pesquisa foi desenvolvida em três etapas, a saber: a) em um primeiro momento, foi realizada uma entrevista com a professora PSR e observações de aulas, tanto na classe comum, como na SRM, com propósitos de compreendermos as concepções da docente, PSR, no que se refere à educação inclusiva bem como conhecer suas estratégias metodológicas aplicadas na leitura e escrita do aluno Davi. Também, foram coletados materiais como laudos especializados da escola, referentes a Davi, e atividades de leitura e de escrita desenvolvidas por esse aluno nos dois contextos observados. A análise dos dados obtidos, dessa etapa, forneceu subsídios para o desenvolvimento das ações colaborativas;

\footnotetext{
${ }^{4}$ A pesquisa colaborativa, que integra o projeto "Linguagem, Letramento e Diversidade", aprovado pela Comissão Permanente de Ética em Pesquisa para Seres Humanos (COPEP), da Universidade Estadual de Maringá, sob o parecer 1693495 .
} 
b) Encontros da pesquisadora colaboradora com a PSR, a fim de realizarem leituras e refletirem sobre o atendimento de alunos com TFE; c) entrevista com a professora PSR e novas observações de aulas em classe comum e SRM, com o intuito de caracterizar as alterações apresentadas pela PSR e por Davi, a partir das mediações colaborativas.

Neste artigo, focalizamos as estratégias metodológicas de leitura e de escrita em classe comum, anteriormente e posteriormente às ações colaborativas. Para tanto apresentamos e discutimos algumas atividades e cenas de interação, de forma a evidenciar as contribuições do trabalho colaborativo, no desenvolvimento da leitura e escrita de alunos com TFE.

\section{Apresentação e análise dos dados}

A princípio, apresentamos algumas estratégias metodológicas aplicadas pela PSR, no processo do trabalho de leitura e escrita, na sala de aula comum, sem, contudo, a interferência/colaboração da pesquisadora.

\section{O ensino da gramática como pressuposto para a leitura}

$\mathrm{Na}$ primeira aula observada, a professora passou uma lista de palavras na lousa. Depois, solicitou aos alunos que separassem essas palavras em sílabas e classificassem-nas de acordo com os encontros vocálicos. Segundo a docente, esse conteúdo foi trabalhado em uma aula anterior. 


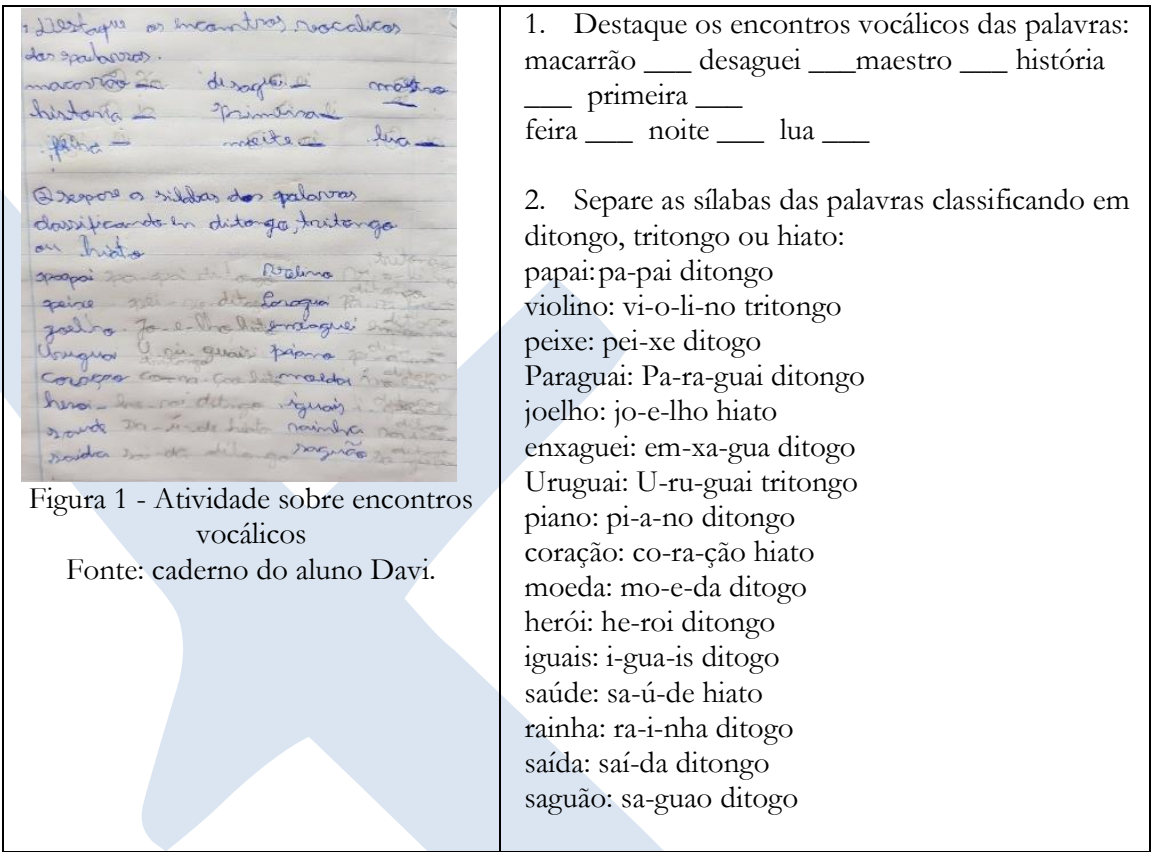

É importante frisarmos que, para a realização dessa atividade, não foram fornecidas explicações detalhadas de como os alunos deveriam resolver, ou seja, sem um exemplo explicativo. A falta dessa, pela docente, gerou dúvidas e confusão, porque os alunos dividiam as palavras em sílabas, mas se confundiam com a classificação silábica, que também tinha sido trabalhada em aulas recentes. A professora prestou atendimento individualizado para alguns alunos que demonstravam maiores dificuldades e, na sequência, fez a correção coletiva, para a qual cada aluno classificava uma palavra. No entanto, as crianças que apresentaram dificuldades, dentre elas o aluno Davi, não conseguiram acompanhar a correção e o exercício foi finalizado sem que maioria dos alunos efetivasse a tarefa. Observamos (Figura 1) que as primeiras palavras da primeira coluna, cujo exercício foi realizado com auxílio da PSR, apresentam as respostas corretas, mas a sequência, mesmo após correção conjunta, permanece sem alteração, com erros na separação silábica e na classificação, como em "saída: saí-da - ditongo","rainha: ra-i-nha - ditogo". 
$\mathrm{Na}$ sequência, a professora solicitou a realização de um terceiro exercício, para o qual deveriam ser unidas sílabas formando palavras com encontros vocálicos:

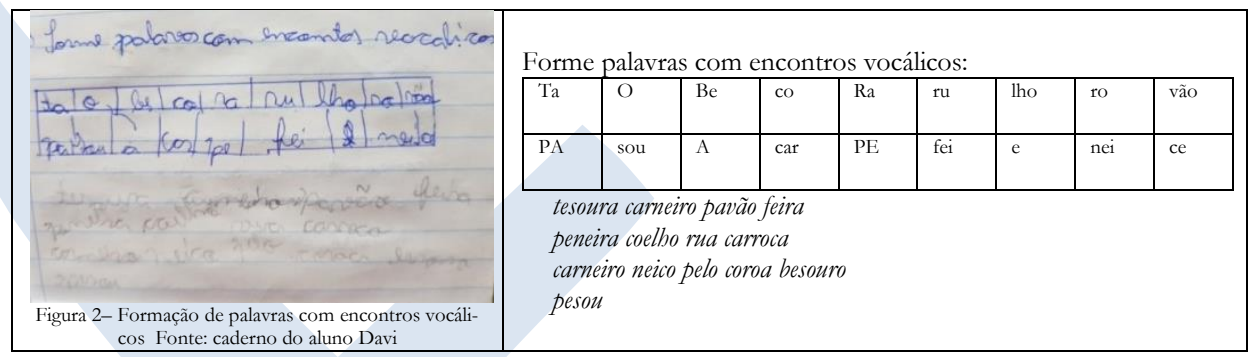

$\mathrm{Na}$ realização da atividade, a maioria dos alunos apresentou grande dificuldade para formar palavras com encontros vocálicos. Algumas palavras também foram escritas em desacordo com a norma padrão e rejeitadas pela professora sem maiores explicações, como "pasou” (passou), "pesoua” (pessoa) e "carroca” (carroça). O aluno Davi apenas copiou as instruções para o exercício sem formar nenhuma palavra. Após a correção conjunta, copiou as palavras citadas pelos colegas, inclusive o substantivo "Neico", apelido do tio de um aluno.

Após, os alunos receberam uma atividade impressa, na qual deveriam pintar com cores específicas palavras que apresentassem ditongos, tritongos e hiatos. Novamente houve muitas dúvidas devido ao fato de os alunos não conseguirem realizar a separação silábica de acordo com a pronúncia adequada (“jue-lho”, em vez de jo-e-lho, por exemplo) e, concomitantemente, não terem compreendido a diferença entre classificação quanto ao número de sílabas e classificação quanto aos encontros vocálicos. Durante a correção feita pela professora, ela mesma confundiu-se várias vezes, classificando palavras de modo equivocado. 


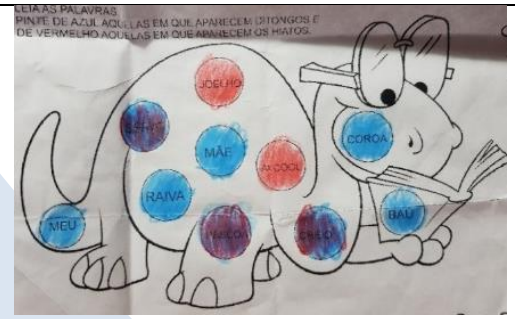

Respostas do aluno: MEU - ditongo, JOELHO - hiato, SÉRIE ditongo corrigido para hiato (equivocado), MÃE - ditongo, ÁLCOOL - hiato, RAIVA - ditongo, PÁSCOA - ditongo corrigido para hiato (equivocado), CHEIO - ditongo corrigido para hiato, COROA - ditongo (equivocado), BAÚ - ditongo (equivocado)

Figura 3 - Atividades sobre encontros vocálico Fonte: caderno do aluno Davi

Podemos observar, na atividade realizada por Davi, que ele coloriu as palavras de modo aleatório, corrigiu algumas de acordo com a orientação dada pela professora à turma, mas não compreendeu de fato o que deveria ser feito e é evidente que a classificação dos encontros vocálicos não se efetivou como um conteúdo significativo.

Assim como Davi, a maioria dos alunos da turma também não conseguiu realizar a tarefa, cujo objetivo era a memorização de um fato gramatical sob a perspectiva normativa, tomado como prerrogativa para a posterior separação silábica das palavras em futuras produções textuais.

Notamos, no exercício da Figura 3, que a professora prioriza a leitura de palavras, muitas vezes desprovidas de sentido para o aluno, e dá importância extrema ao ensino de nomenclaturas, abordando a gramática de forma descontextualizada, sem lhe oportunizar compreensão ou construção das regras. De acordo com os conceitos bakhtinianos (BAKHTIN/VOLOCHINOV, 2006), a palavra desvinculada de um contexto existe apenas como um sinal e, sendo assim, não constitui uma palavra, mas um elemento descaracterizado de sentido, sem conteúdo. Bakhtin/Volochinov (2006, p. 35) discute a atividade linguística como social, pois “[...] realizando-se no processo da relação social, todo signo ideológico e, portanto, também o signo linguístico, vê-se marcado pelo horizonte social de uma época e de um grupo social determinados". O signo linguístico é, portanto, um signo socioideológico, visto que concentra em si valores de um grupo social.

Para Davi, que ainda se encontra no nível de decodificação das palavras, um exercício que exige a leitura, pronúncia vinculada à padronização da língua e separação silábica 
a fim de se inferirem conceitos gramaticais abstratos, configura-se em uma atividade que ele ainda não é capaz de executar, da mesma forma como também muitos de seus colegas que já apresentam proficiência na leitura. Se as concepções abstratas dos signos linguísticos constituem dificuldades para a maioria dos aprendizes, para o aluno que apresenta dificuldades de aprendizagem essas atividades mecanizadas são ainda mais inconsistentes, menos significativas e, se objetivam apenas a memorização de conceitos gramaticais, são desnecessárias, nesse momento da escolarização.

Maia e Bentes (2017) discutem a importância de se desenvolver atividades a partir de várias linguagens que explorem um tema e de se dar acesso à utilização contextualizada da escrita da língua portuguesa.

Fazer a opção em trabalhar com os signos ideológicos não é descartar a escrita e sim somar a ela outras linguagens que possam favorecer no aluno [...] a compreensão do que se quer ensinar, tornando a aprendizagem mais acessível (MAIA; BENTES, 2017, p. 166).

Em se tratando do ensino ao aluno com TFE, a intermediação do professor ou colegas a fim de compreender o que lê, é imprescindível. Quando o ensino de leitura está desvinculado de compreensão concreta e efetiva, ele perde o sentido e gera ainda mais dificuldades embasadas na desmotivação dada pela falta de compreensão. Pode-se tomar como um exemplo ineficaz o exercício da Figura 03.

A realização de atividades que se assemelhem às práticas da vida real é também discutida por Maia e Bentes (2017) e, nessa perspectiva, o conceito base de palavra como signo ideológico (BAKHTIN/VOLOCHINOV, 2006) vai além do ato de ensinar a ler e escrever, engloba a produção de sentido que se dá no decorrer das mais variadas situações mediadas por inúmeros signos ideológicos.

O signo é algo, uma palavra, um gesto, uma imagem, uma manifestação artística que tem um significado ou sentido, que denota um objeto, um acontecimento ou experiência psíquica, que ocorrem nos mais diversos campos da comunicação humana (MAIA; BENTES, 2017, p. 147).

O ensino da leitura e da escrita implica na construção de sentidos que se dá entre os interlocutores, fundamentando-se em fatos reais concretos de comunicação e saberes. 
Desse modo, as dificuldades encontradas pelo aluno Davi na realização da tarefa proposta estão relacionadas à falta de vínculo social da escrita, configurando-se em um exercício de treinamento que não contribuiu para o desenvolvimento do aluno. Sob a perspectiva histórico-cultural, caberia a mediação pedagógica a fim de situar a produção dentro de um uso social da língua, levando o aluno ao desenvolvimento significativo da escrita, à realização de ações que ainda não é capaz de fazer sozinho, mas que conseguiria com auxílio, ampliando, assim, sua ZDP (VYGOTSKY, 1998).

A partir das observações, realizadas na sala de aula da PSR, percebemos:

$\checkmark$ preocupação exacerbada da docente com a teoria e a nomenclatura em detrimento da aplicabilidade contextualizada dos conteúdos estudados;

$\checkmark \quad$ excesso de exercícios baseados em cópia e poucas produções escritas a partir da compreensão e conhecimento desenvolvido pelo aluno;

$\checkmark$ pouca valorização das capacidades individuais, tanto dos alunos que apresentam dificuldades de aprendizagem quanto daqueles que se destacam;

$\checkmark \quad$ organização sistêmica e tradicional com pouca abertura para questionamentos e participação dos alunos;

$\checkmark \quad$ ausência de atividades suplementares para os alunos que apresentam maiores habilidades como ferramenta que permite ao professor efetivar apoio individualizado aos alunos que despendem um tempo maior para a realização dos trabalhos desenvolvidos em sala de aula;

$\checkmark$ pouco aproveitamento das parcerias com colegas mais experientes, atividades em grupos e metodologias diferenciadas que possibilitam o diálogo construtivo entre os pares da turma.

No que se refere ao atendimento a Davi, concluímos que, embora ele seja eventualmente auxiliado pela professora, não é convidado a participar das aulas; suas produções em geral não são revisadas com o intuito de concluí-las, sanar dúvidas, desenvolver aprendizagem. Há uma preocupação excessiva com os registros no caderno do aluno, mesmo 
que na maioria das vezes eles sejam realizados por meio de cópias malfeitas, desmotivadas, desprovidas de compreensão. Faltam noções de acesso ao currículo e valorização das habilidades do aluno que venham a ampará-lo de modo a desenvolvê-lo a partir do que já é capaz de fazer, aumentando sua autoestima e levando-o ao autoconhecimento como ferramenta importante para o seu desenvolvimento.

\section{Um olhar para o leitor e os processos de leitura}

Nessa sessão, discutimos a ação da pesquisadora, a partir do trabalho colaborativo junto à PSR. O ponto de partida foram os resultados das análises e reflexões concernentes às práticas pedagógicas em sala de aula, na qual participava o aluno Davi.

A partir dessa realidade, procedeu-se à busca de textos que pudessem constituir reflexões sobre o espaço da sala de aula, como um processo de interlocução, a partir da percepção de texto como enunciado (BAKHTIN, 2003), isto é, como uma ação linguística viva que se constrói no complexo jogo das relações humanas. Desse modo, foram selecionados dois artigos: “O leitor e o processo da leitura” (MENEGASSI, 2010a) e “O processo de produção textual" (MENEGASSI, 2010b). Os respectivos estudos, dialogando com os pressupostos bakhtinianos de linguagem, discorrem sobre a perspectiva processual de leitura e de escrita, a qual envolve procedimentos graduais capazes de instigar o desenvolvimento paulatino do sujeito leitor e produtor de textos. Isso contribui para fazê-lo passar por várias etapas de mudança, bem como superar suas dificuldades na leitura, na produção textual, alcançando um nível mais crítico, responsivo e autônomo no uso da linguagem.

Os textos foram lidos e discutidos pela pesquisadora e pela PSR, nos espaços de hora-atividade. Concomitantemente, foram desenvolvidas orientações à professora sobre os processos de leitura e de escrita na própria sala de aula. Trazemos, aqui, a título de exemplificação, uma cena de interação entre a pesquisadora (Pesq.) e a PSR, na qual se discutiu os processos de revisão textual-interativa e de reescrita:

PSR: É bom de trabalhar desse jeito, porque eu tinha muita dúvida de como trabalhar um texto, como corrigir... É trabalhoso, mas facilita na sala de aula. 
Pesq.: É muito fácil você corrigir com uma caneta vermelha e colar no caderno do aluno. Mas aí ele não refletiu sobre o que escreveu. E não há aprendizagem.

PSR: Você sabe como a turma é. Tem alunos com muitas dificuldades. Agora eu corrijo como você me ensinou e enquanto os outros alunos vão reescrevendo, organizando os próprios textos, o Davi lê pra mim e vou organizando junto com ele. Do mesmo jeito faço com os outros que não conseguem sozinhos. Mas a cada vez é mais fácil, a gente vai pegando o jeito.

Pesq.: Às vezes a gente se preocupa muito em ensinar gramática, e os nomes 'adjetivo', 'substantivo', 'verbo', mas o que importa, na verdade, é que eles saibam usar adequadamente essas classes de palavras.

PSR: A gente falha, porque a experiência da gente é bem pouca, mas a gente vai aprendendo...

A partir do trabalho conjunto professor/pesquisador em sala de aula, fundamentado por leituras e reflexões acerca das práticas escolares, há o novo olhar do professor sobre as atividades de leitura e escrita e, também, a efetivação de práticas que possibilitam o desenvolvimento de todos os alunos inseridos na sala de aula.

Assim, o papel do interlocutor, tomado aqui ora pela figura do pesquisador mediante o professor, ora pelo professor mediante o aluno, ora pelos próprios alunos mediante si próprios ou seus pares, se faz fundamental no ensino significativo, partindo das necessidades individuais, das demandas sociais, passando por uma elaboração interna do sujeito, por meio da mediação do outro e da atividade em situações efetivas. É o que propõe Vygotsky (1994, p. 156), ao afirmar que “a escrita deve ter significado para as crianças, de que uma necessidade intrínseca deve ser despertada nelas e a escrita deve ser incorporada a uma tarefa necessária e relevante para a vida”.

\section{Resultados da ação colaborativa na prática docente}

As primeiras observações, nas aulas da PSR, apontaram para a necessidade de se redimensionar as práticas pedagógicas em prol do desenvolvimento da leitura e da escrita do aluno com TFE. Percebemos um trabalho direcionado ao ensino de gramática, em que os textos e as leituras serviam de pretexto para exercícios de classificação de palavras. As 
produções escritas eram criticadas pela falta de criatividade e excesso de erros cometidos e a professora mencionava a dificuldade na realização da correção individual, em especial dos alunos que não escreviam 'nada'. Assim, os textos eram corrigidos de modo a pontuar erros de gramática e de ortografia e não havia retorno para uma reescrita.

A partir das reflexões, por meio das ações colaborativas, a PSR organiza práticas diferenciadas em sala de aula, pautando-se nos pressupostos da concepção dialógica de linguagem (BAKHTIN/VOLOCHINOV, 2006; BAKHTIN, 2003). Desse modo, observa-se que os alunos vão semanalmente à biblioteca, onde cada um escolhe um livro e, durante a semana, apresenta oralmente o enredo aos colegas de sala de aula, cada qual fazendo observações sobre o que achou relevante no texto lido, em um exercício efetivo de réplicas aos enunciados (BAKHTIN/VOLOCHINOV, 2006). Essa prática, ao longo das aulas observadas, tem desenvolvido não só o interesse pela leitura, mas a oralidade, a consciência das funções de locutor e interlocutor e a desenvoltura na organização de ideias a fim de se falar em público. Ademais, a leitura prevê contextos de interlocução, dialógicos, sociais, que repercutem inferências, críticas, elaborações intrapessoais - processos evidenciados nas ações colaborativas a partir das discussões acerca das etapas do processo de leitura (MENEGASSI, 2010a) - que não se constroem por meio da leitura de palavras soltas ou frases descontextualizadas, conforme evidenciávamos no início da pesquisa.

Ao iniciar o trabalho com o aluno Davi, apontamos, entre as características observadas, um excesso de timidez, o medo do fracasso, a ausência total de questionamentos ou posicionamentos em sala de aula e, também, nenhum relacionamento com os colegas. Resultante do trabalho colaborativo, podemos observar nesta etapa um aluno mais confiante, comunicativo e participativo. Em uma das atividades de leitura, Davi foi auxiliado na leitura do livro que escolheu, 'Lugar de bicho'5, e fez questão de apresentá-lo à turma, contando a

5 TÁVORA, Viviane Veiga. Lugar de bicho. Ilustração Clara Glavilan. São Paulo: Guia dos Curiosos Comunicações. 2013. 
história e mostrando aos colegas as ilustrações. Por essa atitude, evidenciamos a importância que o professor desempenha perante o aluno: as contrapalavras, o despertar da curiosidade, o estímulo à descoberta através da leitura, a promoção das habilidades individuais, a elaboração de atividades e situações significativas, não somente com o aluno que apresenta dificuldades, mas com toda a turma, que reconhece e respeita os ritmos e particularidades de cada colega.

Angelo (2015), retomando os conceitos de Vygotsky (1994), aborda a mediação como um processo que caracteriza a relação do ser humano com o mundo, relação que acontece por intermédio de um elemento de intervenção e não de forma direta. Trata-se de uma relação onde "o processo simples estímulo-resposta é substituído por um ato complexo, mediado" (VYGOTSKY, 1994, p. 53). Podemos observar, no contexto da pesquisa, que uma transformação externa, expedida pelo trabalho colaborativo modificou as atitudes da PSR que, por sua vez, conduziu uma função mediadora orientando o aluno Davi. Esse aluno passa a transformar as próprias atitudes, o que constitui, nos termos de Leontiev (2004, p. 318), "a verdadeira fonte do desenvolvimento humano".

$\mathrm{O}$ trabalho direcionado à leitura de diferentes textos, realizado de forma silenciosa e sem abertura para questionamentos e compreensão, e que se resumia ao pareamento de informações, cedeu lugar a atividades significativas, com propostas de pré-leitura, abertura para questionamentos e perguntas de leitura que levam o aluno a localizar informações explícitas, mas também exigem a compreensão de fatos implícitos ao texto, exigindo posicionamento e compreensão de mundo. Percebemos o desenvolvimento de habilidades de leitura (MENEGASSI, 2010a) cada vez mais consistentes nas práticas da professora e dos alunos.

Uma das atividades propostas teve como base um texto curto, intitulado "O palhaço Caolho”, de Graça Batituci. Antes de distribuir o texto, a PSR realiza uma atividade de préleitura e leva os alunos à construção de expectativas, motivando-os à leitura: 
PSR: Hoje vamos ler um texto que tem como título 'O palhaço Caolho’ (escreveu o título no quadro). Quem sabe me dizer o que é 'caolho'?

Aluno: É igual um pirata que só enxerga com um olho... PSR: Isso mesmo. Então esse palhaço deve enxergar só com um olho?

Alunos: Sim... É...

PSR: E por que esta palavra foi escrita com letra maiúscula? Alunos: Porque é o nome dele!

PSR: Exatamente. Caolho é o nome do palhaço... E como vocês acham que o Caolho pode ser?

Alunos: Engraçado... ele dá cambalhotas... não enxerga direito...

PSR: Vou entregar os textos e quero que vocês leiam com muita atenção. Vamos conhecer o Caolho?

Notamos, no direcionamento dado pela PSR, que a atividade é conduzida de acordo com os processos de leitura, prática que passa a ser rotina nas atividades com diferentes gêneros discursivos apresentados à classe. Embora ainda se utilize de um texto produzido para o ensino de ortografia, PSR não se prende à localização de palavras que são escritas com o dígrafo que pretende fixar, mas explora informações do texto que colaboram para o desenvolvimento de uma leitura atenta e produtiva cujo objetivo é 'conhecer o Caolho', e não ler para responder perguntas sobre o texto.

\section{- Palhaço Gaolho}

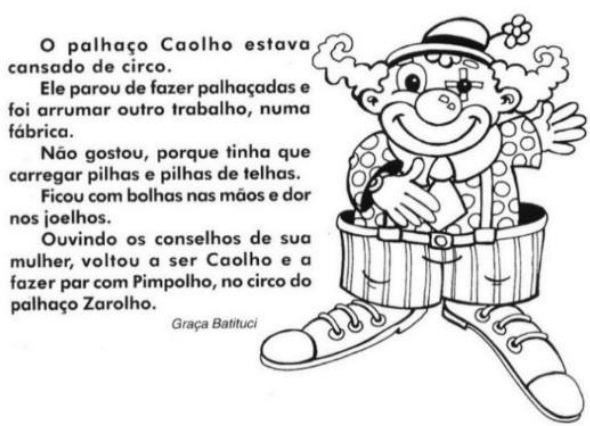

Figura 4 - 'Texto 'O palhaço Caolho' Fonte: diário do professor. 
É solicitada uma leitura silenciosa, para que os alunos construam sentidos individuais para a leitura. Após esclarecer algumas dúvidas concernentes ao vocabulário, a professora PSR solicita a leitura em voz alta, para a qual proporciona oportunidade para que todos os alunos leiam um parágrafo, repetindo o texto algumas vezes. Importante destacar que nenhum aluno se recusa a fazê-lo e, mesmo em face das dificuldades observadas na leitura de alguns alunos, dentre os quais, Davi, a turma permanece em silêncio, respeitando as individualidades e o ritmo dos colegas.

Davi lê o parágrafo lentamente, após ter sido auxiliado pelo colega da frente a se localizar no texto. Sua leitura, nas palavras constituídas por sílabas complexas, ainda é silabada, pois se encontra ainda em processo de formação como leitor, mas não se observa receio ao fazê-lo, de acordo com suas possibilidades. É perceptível a satisfação que sente ao finalizar a tarefa, numa atitude de superação, autoconhecimento, autoconfiança e entrosamento com os colegas.

As metodologias adotadas pela professora estabeleceram práticas que passaram a ser vivenciadas em sala de aula, garantindo a participação de todos os alunos. Nas últimas entrevistas, a professora afirma: "Eu notei diferença no Davi, até as notas dele melhorou... só que eu notei assim... que agora a gente elogiou ele, a mãe ficou feliz que ele tirou tudo nota boa, e ele deu uma relaxada, sabe... Hoje eu coloquei ele perto da minha mesa... troquei de lugar na sala porque ele tava só conversando... e ele era um aluno que nem levantava, né? Ele não se relacionava com ninguém... [...] ele evoluiu bastante e os colegas não julgam as dificuldades que ele tem..."

Os posicionamentos, de acolhida e de valorização das capacidades individuais, da PSR, por meio de interações em diversos níveis, foram responsáveis pela mudança de atitude do aluno, que outrora permanecia sentado, silencioso, sem questionar ou manter contato com os colegas. A sociabilização de pessoas tão diferentes entre si, o respeito pelas dificuldades e potencialidades passa a ser uma realidade na turma que Davi frequenta, resultado de uma mudança de atitude pedagógica. 
Na sequência da atividade relativa ao texto, a PSR faz questionamentos aos alunos: primeiramente, de modo oral e depois por meio de perguntas escritas, os quais levaram o aluno a não, somente, parear respostas, mas inferir informações: "Por que o Caolho se cansou do circo?" e "O que o levou a voltar?", por exemplo. Percebemos, assim, que a professora evidencia maturidade perante os processos de leitura, levando seus alunos, através de importantes ações pedagógicas, a refletirem sobre o texto, fazendo inferências que não estão explícitas, mas que são fundamentais à formação do leitor consciente.

No que se refere a Davi, no início da pesquisa observamos um aluno inseguro, com dificuldades nas habilidades mais simples, como localizar informações explícitas ao texto. A partir do desenvolvimento de leitura compartilhada, das atividades de pré-leitura, das perguntas de leitura que assegurem não apenas a reprodução de dados do texto, mas as inferências e a interpretação, e o trabalho com textos significativos, percebemos o desenvolvimento de Davi, que se mostra capaz de realizar leitura silenciosa identificando informações explícitas, estabelece inferências mais simples e interpreta textos com auxílio do professor ou colegas, manifestando um ponto de vista acerca do que foi lido e compreendido; desse modo, observa-se o desenvolvimento de capacidades para níveis mais elevados de leitura que o conduzem como um leitor cada vez mais ativo perante o texto.

Os dados trazidos nesta pesquisa tornam evidente o fato de que a formação continuada, com o trabalho colaborativo mediado pelo outro mais experiente, é capaz de proporcionar mudanças visíveis que ocorrem no interior dos indivíduos transformando definitivamente suas práticas e seu modo de ver o mundo que o cerca.

\section{Nossas considerações}

Em nossas observações, no decorrer da pesquisa, percebemos a tentativa de uma docente em trabalhar exercícios de língua portuguesa junto ao aluno com TFE. Contudo, suas estratégias metodológicas focavam apenas cópias e atividades descontextualizadas. Os resultados, portanto, se traduziram em desestímulos em ambos os envolvidos, professor e 
aluno. Davi, aluno com TFE, apresentava dificuldades na escrita, na seleção de informações, organização de ideias e pontuação; demonstrava poucas habilidades de compreensão leitora, como realizar antecipações de informações acerca do conteúdo do texto, localizar informações e inferir. Além disso, mostrava-se inseguro no trato com o outro, introspectivo, e evidenciava a supervalorização do erro em detrimento dos seus acertos, em uma visível incorporação do fracasso escolar.

A mudança de atitude do professor em sala de aula, a partir das atividades de formação desenvolvidas no decorrer da pesquisa, oportunizaram que a aprendizagem partisse da valorização dos saberes do aluno despertando nele a curiosidade pela leitura e o desenvolvimento da escrita, ampliando progressivamente suas habilidades.

A partir dessas considerações, compreendemos como a mediação pedagógica colaborativa contribui para a prática efetiva da docência e para a aprendizagem do aluno que apresenta TFE, relacionados à dificuldade em ler e escrever. Constatamos que as práticas pedagógicas após as ações colaborativas apresentam importantes alterações, justificadas pelos pressupostos da concepção dialógica de linguagem e da teoria histórico-cultural, pelas quais as inter-relações desenvolvidas perante o contato com o outro, com instrumentos e signos, proporcionam a interiorização de novos conceitos que, paulatinamente, são internalizados e transformados em práticas e palavras próprias. Assim, verificamos ações pedagógicas voltadas à superação de dificuldades individuais, interações dialógicas pontuais entre professor e aluno a fim de dar subsídios para o desenvolvimento intrapessoal, além de ações que incentivam a participação de todos os alunos, valorizando habilidades e respeitando diferenças, práticas de leitura e de escrita que mobilizam os conhecimentos prévios dos alunos e impulsionam à descoberta e à ampliação de capacidades individuais.

Dessa forma, pontuamos a importância da formação continuada como fonte de enriquecimento para os processos pedagógicos desenvolvidos por uma escola que, muitas vezes, cristaliza-se em metodologias tradicionalistas, que utilizam o texto como pretexto para o ensino de ortografia e normas gramaticais, que avaliam e ensinam alunos pretensa- 
mente homogêneos. Nesse sentido, é preciso que se propiciem condições para que professores e alunos possam dialogar com a diversidade de enunciados presentes no cotidiano, de forma crítica e abrangente. Faz-se necessária, ainda, a busca de alternativas que levem à apropriação do conhecimento para a diversidade de alunos que compõem as salas de aula, valorizando-se seus conhecimentos prévios, suas habilidades e respeitando-se seus limites.

\title{
PRACTICES OF COLLABORATIVE TRAINING IN THE PROCESS OF READING AND WRITING OF A STUDENT WITH SPECIFIC FUNCTIONAL TRANSTORN
}

\begin{abstract}
This article aims to discuss how collaborative pedagogical mediation contributes to teaching and to student learning that presents specific functional disorders - FET, related to difficulties in reading and writing. With theoretical foundations in the Bakhtin Circle studies and in the historical-cultural theory, starting from Vygotsky, and with methodological basis in the assumptions of the collaborative research, we tried to orient a teacher of the 4th year of elementary school in the work with the reading and the written to the student who has TFE. The results demonstrate the teacher 's attitude change in the classroom, based on the training activities developed, since it starts to value the student' s knowledge and to practice reading and writing practices based on the dialogical principles; also show significant advances of the student with $\mathrm{OE}$ in their development, not only in reading and writing, but also in their social relations.
\end{abstract}

KEYWORDS: Specific functional disorders; Reading and writing; Continuing education; Collaborative research.

\section{REFERÊNCIAS}

ANGELO, C. M. P. Mediações colaborativas e pedagógicas em Sala de Apoio à Aprendizagem de Lingua Portuguesa. 390 f. Tese (Doutorado em LETRAS) - Programa de Pós-Graduação em Letras, Maringá, 2015. Disponível em: <http://www.ple.uem.br>. Acesso em 10 mar. 2019.

BAKHTIN, M. Estética da criação verbal. São Paulo: Martins Fontes, 2003 [1979]. [1929].

; VOLOCHINOV, V. N. Marxismo e filosofia da linguagem. São Paulo: Hucitec, 2006 
BLUM, M. A. B. Ações colaborativas em contexto escolar: o ensino da leitura e da escrita junto ao aluno com transtornos funcionais específicos. 2019. Dissertação (Mestrado em Letras) - Universidade Estadual do Centro-Oeste - UNICENTRO, Guarapuava, 2019.

BRASIL. Decreto n ${ }^{\circ}$ 6.949/2009. Convenção Internacional sobre os Direitos das Pessoas com Deficiência. Brasília, 2009. Disponível em: <http://www.planalto.gov.br/ccivil_03/_ato20072010/2009/decreto/d6949.htm.> Acesso em 03 dez. 2017.

DESGAGNÉ, S. O conceito de pesquisa colaborativa:a ideia de uma aproximação entre pesquisadores universitários e professores práticos. Tradução de FERREIRA, Adir Luiz; SOUZA, Margarete Vale. Revista Educação em Questão, Natal, v. 29, n. 15, p. 7-35, maio/ago. 2007.

JESUS, D. M.; ALMEIDA, M. L.; SOBRINHO, R. C. Pesquisa-ação-crítico-colaborativa: implicações para a formação continuada e a inclusão escolar. In: REUNIÃO ANUAL DA ANPED, 28., 2005, Caxambu/MG. Anais... Caxambu/MG, 2005. Disponível em <http://28reuniao.anped.org.br/textos/minicursos/denise_meyrelles_jesus.doc $>$. Acesso em 13 set. 2017.

LEONTIEV, A. N. O desenvolvimento do psiquismo. Tradução de Rubens Eduardo Frias. 2.ed. São Paulo: Centauro, 2004.

MAIA, T. C. V.; BENTES, J. A. de O. Cenas de letramento e multiletramento em uma escola de crianças surdas de Belém. In: BENTES, J. A. de O.; RODRIGUES, I. C. F. dos S. Linguagens e práticas docentes: relações bakhtinianas. São Carlos: Pedro \& João Editores, 2017. p. 145-171.

Manual diagnóstico e estatístico de transtornos mentais [recurso eletrônico] : DSM-5 / [American PsychiatricAssociation ; tradução: Maria Inês Corrêa Nascimento ... et al.] ; revisão técnica: Aristides Volpato Cordioli ... [et al.]. - 5. ed. - Dados eletrônicos. - Porto Alegre : Artmed, 2014.

MENEGASSI R. J. O leitor e o processo de leitura. In: GRECO, E. A.; GUIMARÃES, T. B. (Orgs.) Leitura: aspectos teóricos e práticos. Maringá: Eduem, 2010a. p. 35-59.

. O processo de produção textual. In: SANTOS, A. R. dos; GRECO, E. A.; GUIMARÃES, T. B. (Orgs.). A produção textual e o ensino. Maringá: Eduem, 2010b. p. 75-101.

PARANÁ. Conselho Estadual de Educação. Deliberação 02/2016. Dispõe sobre as Normas para a Modalidade Educação Especial no Sistema Estadual de Ensino do Paraná. Curitiba, 2016.

STREIECHEN, E. M. Um estudante bilingue, uma mãe surda e a escola: percurso de encontros, desencontros e contradições. Tese (Doutorado em Educação). Programa de Pós-Graduação da Universidade Estadual de Ponta Grossa/Paraná, 2018. 
UNESCO. Coordenadoria Nacional para a Integração da Pessoa Portadora de Deficiência (CORDE). Declaração de Salamanca de princípios, política e prática para as necessidades educativas especiais. Brasília: CORDE, 1994

VYGOTSKY, L. S. A formação social da mente. 4. ed. São Paulo: Martins Fontes, 1991. - A formação social da mente: o desenvolvimento dos processos psicológicos superiores. (Orgs.). Michael Cole et al. Tradução José Cipolla Neto, Luis Silveira Mena Barreto, Solange Castro Afeche. 6. ed. São Paulo: Martins Fontes, 1998.

Recebido em: 01/06/2019. Aprovado em: 17/07/2019. 